A - preparing concepts

$\mathrm{B}$ - formulating methods

$\mathrm{C}$ - conducting research

$\mathrm{D}$ - processing results

E - interpretation and conclusions

$\mathrm{F}$ - editing the final version

\title{
The influence of lower limbs muscle strength and power on the functional performance of women with back pain syndromes
}

\author{
Julia Kubielska*A-D iD, Elżbieta Miller ${ }^{B, E-F}$ (iD, Joanna Kostka ${ }^{A-C, E-F}$ (D) \\ Department of Neurological Rehabilitation, Medical University of Łódź, \\ Poland
}

*Correspondence: Julia Kubielska; Department of Neurological Rehabilitation, Medical University of Łódź, Milionowa 14, 93-11 Łódź; email: jkubielska@onet.pl

\begin{abstract}
Introduction: The purpose of the study was to assess the occurrence of deficits in strength and power of lower limb muscles and functional performance of patients with back pain syndromes and to identify the factors that affect them.

Material and methods: The clinical material consisted of 43 patients ( 28 women with back pain syndrome, the control group - 15 people). Up\&go test, Barthel Index, five-time standing up test, Tinetti test, assessment of power (Pmax), strength and optimal shortening velocity (Vopt), Geriatric Depression Scale (GDS), pain assessment were performed in all patients.

Results: The patients from the control group achieved better results in the five-time standing-up test $(p=0.006)$, in the Tinetti test $(p=0.04)$ and had higher knee extensors muscle strength $(p=0.005)$. Functional performance in patients with lumbosacral spine pain syndromes was determined by the strength of the knee extensors muscles (Up\&go test Rho $=0.54 ; p=0.005$; five-time standing up test $\mathrm{Rho}=0.39 ; \mathrm{p}=0.04$; Tinetti for gait $\mathrm{Rho}=0.4 ; \mathrm{p}=0.04)$. Age and height influenced the parameters of muscle function.

Conclusions: Patients with back pain syndromes are characterized by reduced functional performance and have knee extensors muscle deficit in relation to people without back pain. Knee extensors muscle strength has the greatest impact on functional performance in patients with back pain. Younger and taller people have better results in muscle function tests.
\end{abstract}

Keywords: strength measurement, muscle function, gait quality, functional tests, spine pain

\section{Introduction}

Back pain is of interest in many fields of medicine [1]. They are a symptom that accompanies various types of diseases. Almost $80 \%$ of the population suffer from pain due to spine dysfunction. Awareness of the dangers resulting from the further development of civilization, the more and more frequent avoidance of physical activity and the common pain complaints of the spine encourage the search for effective methods to oppose these threats $[1,2]$. As part of preventive actions, mainly patient education is carried out, which should increase patient's awareness of the pathomechanisms of back pain, as well as the consequences that 
may result from the lack of knowledge about pro-health behaviours [3].

All kinds of pathologies of the spine and peri-spine tissues may impair its functions, which include: protection of the spinal cord, body support function and stabilization [2]. These disorders can significantly affect the deterioration of functional efficiency, that is the ability to be independent in terms of basic and complex activities of everyday life [4].

The condition of the muscles may influence the functioning of the spine directly (paraspinal muscles) or indirectly (e.g. muscles of the lower limbs), influencing the positioning and operation of segments related to the spine. In turn, restriction of physical activity caused by pain and fear of the worsening of symptoms may reduce muscle strength and power. Patients with back pain also show a tendency to inhibit muscle activity, which may affect the results of measurements of muscle function parameters [5].

The purpose of the study was to assess the occurrence of deficits in strength and power of lower limb muscles and functional performance in patients with back pain syndromes in relation to healthy people and to identify factors that affect them.

\section{Material and methods}

The clinical material consisted of 43 women - patients of the Department of Daily Rehabilitation at the Jonscher Municipal Medical Center dr Karol Jonscher in Łódź. The study group (study group A) consisted of 28 adult women with pain syndromes of the lumbosacral part of the spine, while the control group consisted of 15 patients with no spinal health problems.

Due to the fact that age is an important determinant of muscle function, in order to determine the actual deficits in strength, muscle power and functional efficiency of patients with back pain syndromes in relation to people without such problems, 20 women were selected in age-matched control group from study group A (study group B).

The tests were carried out on people capable of understanding and executing commands and without general contraindications to perform stress tests. The study excluded people with health problems that prevented functional tests and those whose diseases could directly affect the level of power and strength of the muscles of the lower extremities, except for pain in the lumbosacral part of the spine (people after a stroke, with serious orthopedic problems, having joint prostheses, with a significant limitation of the range of motion and with large changes in muscle tone to a degree that limited the ability to perform planned tests and examinations).

All patients gave written consent to participate in the study and obtained the consent of the main doctor. The project was approved by the Bioethics Committee of the Medical University of Łódź (RNN/130/17/KE from April 17, 2017).

All patients completed a questionnaire that contained questions about their basic data, education, characteristics of the back pain syndrome, previous rehabilitation, possible spine injury, current functional ability, comorbidities and lifestyle. The characteristics of the studied groups (metric data) are presented in Table 1.

The Up\&go test, the Barthel 20-point Index, the fivetime standing test and the Tinetti test were used to assess the functional ability. During the Up\&go test, the patient is asked to get up from the chair, walk a distance of 3 meters, turn around, come back and sit on the chair. The transition time is measured from the command that starts the test until you sit on the chair [6]. The Barthel Index assesses efficiency in terms of ten basic activities of everyday life, rated from 0 to 2 points for each question (a total of max 20 points) [7]. During the five-time standing up test, the patient is instructed to get up from the chair without the help of the upper limbs, which the patient places crosswise on the chest. The patient is asked to repeat this operation five times as quickly as possible. The time it took to complete this task is recorded. The

Tab. 1. Characteristics of studied groups (metric data)

\begin{tabular}{lcccc}
\hline & $\begin{array}{c}\text { Study group (A) } \\
\text { Me (Q1-Q3) } \\
(\mathrm{n}=28)\end{array}$ & $\begin{array}{c}\text { Study group (B) } \\
\text { Me (Q1-Q3) } \\
(\mathrm{n}=20)\end{array}$ & $\begin{array}{c}\text { Control group } \\
\text { Me (Q1-Q3) } \\
(\mathrm{n}=15)\end{array}$ & $\begin{array}{c}\text { Significance level }(\mathrm{p}) \\
\text { (study group B vs } \\
\text { control group) }\end{array}$ \\
\hline Age (years) & $66.0(60.0-73.5)$ & $60.5(57.0-68.0)$ & $59.0(50.0-64.00)$ & 0.53 \\
Body weight $(\mathrm{kg})$ & $73.0(66.0-80.0)$ & $73.5(68.0-81.5)$ & $70.0(61.0-83.0)$ & 0.61 \\
Growth $(\mathrm{m})$ & $1.64(1.59-1.69)$ & $1.64(1.61-1.70)$ & $1.64(1.60-1.68)$ & 0.57 \\
BMI $\left(\mathrm{kg} / \mathrm{m}^{2}\right)$ & $27.7(24.4-29.1)$ & $27.6(14.4-28.8)$ & $25.4(24.0-32.3$ & 0.82 \\
Number of years of education & $13.0(12.0-17.0)$ & $14.0(12.0-17.0)$ & $15.0(12.0-17.0)$ & 0.92 \\
Number of comorbidities & $2.9(2.0-4.0)$ & $3.0(2.0-3.5)$ & $1.0(0.0-2.0)$ & 0.002 \\
\hline
\end{tabular}


stopwatch stops when the patient is in a standing position for the last time. The Tinetti test is a balance and gait scale that indirectly measures the risk of falls.

The Geriatric Depression Scale (GDS) was used to assess the mental state. This scale is used to assess the state of well-being of the respondent during the last 2 weeks. The 15-question version was used [8]. The level of pain and its characteristics were determined using the Numeric Pain Scale [9] and the Laitinen Scale. The Laitinen Scale allows to assess pain in terms of 4 features: frequency of occurrence, intensity, limitation of physical activity and the use of painkillers [10]. Muscle strength of knee extensors and flexors was measured using a Hoggan microFET2 dynamometer with a strain gauge sensor. Seated patients with thighs supported and lower legs following verbal instructions were supposed to perform an extension test and then bend the knee by pressing the device with as much force as possible for about 5 seconds. The points of application of the dynamometer are the distal part of the front (for measuring the extensor strength) and the rear (for measuring the flexor strength) surface of the lower leg. Each patient had two attempts to measure and a better result was used for the study. Muscle strength is given in newtons.

The results of muscle strength and power are given in absolute values and converted to a kilogram of body weight.
Muscle power (Pmax) and optimal shortening velocity (Vopt) were determined during a test on a cyclo ergometer. Details of the methodology were described in the previous work [11].

\section{Statistical analysis}

The test results were prepared on the basis of the "STATGRAPHICS" Plus 5 program. The data were checked for normality of distribution and equality of variances (Shapiro-Wilk test). The Mann-Whitney $\mathrm{U}$ test was used to compare the groups (study group B vs control group). The correlations between the numerical data for the study group A $(n=28)$ were assessed using the Spearman correlation coefficient. The results are presented as the median, lower and upper quartile. The level of statistical significance was set to $p \leq 0.05$.

\section{Results}

The characteristics of the study and control groups are presented in Table 2.

Patients in the study group had a greater number of comorbidities than patients in the control group (Table 1). Significant differences could also be noticed in the result of the five-time standing up test (in the study group this activity was performed at a slower time) and

Tab. 2. Comparison of the study and control groups

\begin{tabular}{|c|c|c|c|c|c|}
\hline & & $\begin{array}{l}\text { Study group (A) } \\
\text { Me (Q1-Q3) } \\
(\mathrm{n}=28)\end{array}$ & $\begin{array}{l}\text { Study group (B) } \\
\text { Me (Q1-Q3) } \\
(\mathrm{n}=20)\end{array}$ & $\begin{array}{l}\text { Control group } \\
\text { Me (Q1-Q3) } \\
(\mathrm{n}=15)\end{array}$ & $\begin{array}{l}\text { Significance level (p) } \\
\text { (study group B vs } \\
\text { control group) }\end{array}$ \\
\hline \multicolumn{2}{|c|}{ Up\&go Test (s) } & $6.7(5.7-8.7)$ & $6.1(5.6-7.25)$ & $5.3(4.5-7.0)$ & 0.08 \\
\hline \multicolumn{2}{|c|}{ Barthel Index } & $20.0(20.0-20.0)$ & $230.0(19.5-20.0)$ & $20.0(20.0-20.0)$ & 0.21 \\
\hline \multicolumn{2}{|c|}{ Five-time standing test (s) } & $10.9(8.6-14.4)$ & $10,7(9.6-13.5)$ & $7.4(6.0-9.4)$ & 0.006 \\
\hline & Gait & $12.0(10.5-12.0)$ & $12.0(10.5-12.0)$ & $12.0(12.0-12.0)$ & 0.45 \\
\hline \multirow[t]{2}{*}{ Tinetti Test } & Balance & $15.5(13.0-16.0)$ & $14.5(11.0-16.0)$ & $16.0(15.0-16.0)$ & 0.07 \\
\hline & Sum & $26.0(24.5-28.0)$ & $25.5(23.0-28.0)$ & $28.0(27.0-28.0)$ & 0.04 \\
\hline \multicolumn{2}{|l|}{ GDS } & $2.8(1.5-4.0)$ & $2.0(1.0-4.0)$ & $2.0(1.0-5.0)$ & 0.97 \\
\hline \multicolumn{2}{|c|}{ Fext $(\mathrm{N})$} & 219.1(188.9-252.5) & 224.1(189.9-259.2) & $279.4(230.5-309.1)$ & 0.005 \\
\hline \multicolumn{2}{|c|}{ Fext/kg body mass (N/kg) } & $3.1(2.6-3.5)$ & $3.1(2.8-3.5)$ & $3.9(3.2-4.6)$ & 0.01 \\
\hline \multicolumn{2}{|c|}{ Fflex $(\mathrm{N})$} & $141.9(127.3-160.9)$ & $155.3(137.9-171.7)$ & $158.4(145.0-194.4)$ & 0.42 \\
\hline \multicolumn{2}{|c|}{ Fflex/kg body mass(N/kg) } & $2.0(1.7-2.2)$ & $2.1(1.8-2.3)$ & $2.3(2.0-2.6)$ & 0.16 \\
\hline \multicolumn{2}{|c|}{$\operatorname{Pmax}(W)$} & $242.8(200.3-324.8)$ & $262.2(226.2-355.8)$ & $306.1(245.3-383.9)$ & 0.36 \\
\hline \multicolumn{2}{|c|}{ Pmax/kg body mass(W/kg) } & $3.5(2.8-4.2)$ & $3.6(3.2-4.6)$ & $4.6(3.5-5.2)$ & 0.19 \\
\hline \multicolumn{2}{|c|}{ Vopt (rpm) } & $67.2(59.7-72.9)$ & $71.2(62.6-77.3)$ & $76.1(64.6-90.3)$ & 0.12 \\
\hline
\end{tabular}

GDS - Geriatric Depression Scale, Fext - muscle strength of knee extensors, Fflex - muscle strength of knee flexors, Pmax - maximum power, Vopt - optimal shortening velocity. 
in the Tinetti test (in the control group, the final result of the Tinetti test was higher). Muscle strength of knee extensors was higher in the control group.

Factors affecting functional performance in patients with lumbosacral spine pain syndromes are presented in Table 3.

Age did not correlate with most tests, except for the Up\&Go test. The younger the patient was, the faster he covered the distance during the test. The patient's weight had an influence on the Tinetti gait test. People who weighed less received more points. The height of the body determined the result of the Up\&go test. The shorter the patient was, the faster he moved during the test. The number of chronic diseases also had a great influence on the result of the Up\&go test. The more chronic diseases a patient had, the longer it took him

Tab. 3. Factors affecting functional performance in patients with lumbosacral spine pain syndromes $(n=28)$

\begin{tabular}{|c|c|c|c|c|c|c|}
\hline & \multirow{2}{*}{ Up\&go Test (s) } & \multirow{2}{*}{$\begin{array}{l}\text { Barthel } \\
\text { Index }\end{array}$} & \multirow{2}{*}{$\begin{array}{c}\text { Five-time standing } \\
\text { up test (s) }\end{array}$} & \multicolumn{3}{|c|}{ Tinetti Test } \\
\hline & & & & Gait & Balance & Sum \\
\hline Age (years) & $\begin{array}{c}\text { Rho }=0.49 \\
P=0.01\end{array}$ & $\begin{array}{c}\text { Rho }=0.13 \\
P=0.51\end{array}$ & $\begin{array}{c}\text { Rho }=0.08 \\
P=0.68\end{array}$ & $\begin{array}{c}\text { Rho }=-0.08 \\
P=0.68\end{array}$ & $\begin{array}{c}\text { Rho }=0.30 \\
P=0.12\end{array}$ & $\begin{array}{c}\text { Rho }=0.21 \\
P=0.27\end{array}$ \\
\hline Body mass (kg) & $\begin{array}{c}\text { Rho }=-0.27 \\
P=0.16\end{array}$ & $\begin{array}{c}\text { Rho }=-0.12 \\
P=0.53\end{array}$ & $\begin{array}{c}\text { Rho }=-0.13 \\
P=0.51\end{array}$ & $\begin{array}{c}\text { Rho }=-0.43 \\
P=0.02\end{array}$ & $\begin{array}{c}\text { Rho }=-0.34 \\
P=0.21\end{array}$ & $\begin{array}{c}\text { Rho }=-0.34 \\
P=0.07\end{array}$ \\
\hline Growth (m) & $\begin{array}{c}\text { Rho }=-0.39 \\
P=0.04\end{array}$ & $\begin{array}{c}\text { Rho }=0.006 \\
P=0.98\end{array}$ & $\begin{array}{c}\text { Rho }=-0.02 \\
P=0.91\end{array}$ & $\begin{array}{c}\text { Rho }=-0.03 \\
P=0.86\end{array}$ & $\begin{array}{c}\text { Rho }=-0.16 \\
P=0.40\end{array}$ & $\begin{array}{c}\text { Rho }=-0.17 \\
P=0.37\end{array}$ \\
\hline BMI $\left(\mathrm{kg} / \mathrm{m}^{2}\right)$ & $\begin{array}{c}\text { Rho }=-0.12 \\
P=0.55\end{array}$ & $\begin{array}{c}\text { Rho }=-0.05 \\
P=0.79\end{array}$ & $\begin{array}{c}\text { Rho }=-0.17 \\
P=0.38\end{array}$ & $\begin{array}{c}\text { Rho }=-0.45 \\
P=0.02\end{array}$ & $\begin{array}{c}\text { Rho }=-0.14 \\
P=0.48\end{array}$ & $\begin{array}{c}\text { Rho }=-0.23 \\
P=0.22\end{array}$ \\
\hline $\begin{array}{l}\text { Number of years } \\
\text { of education }\end{array}$ & $\begin{array}{c}\text { Rho }=-0.14 \\
P=0.47\end{array}$ & $\begin{array}{c}\text { Rho }=-0.26 \\
P=0.17\end{array}$ & $\begin{array}{c}\text { Rho }=-0.07 \\
P=0.72\end{array}$ & $\begin{array}{c}\text { Rho }=0.09 \\
P=0.62\end{array}$ & $\begin{array}{c}\text { Rho }=-0.32 \\
P=0.09\end{array}$ & $\begin{array}{c}\text { Rho }=-0.28 \\
P=0.15\end{array}$ \\
\hline $\begin{array}{l}\text { Duration of back } \\
\text { problems (years) }\end{array}$ & $\begin{array}{c}\text { Rho }=0.15 \\
P=0.43\end{array}$ & $\begin{array}{c}\text { Rho }=0.34 \\
P=0.08\end{array}$ & $\begin{array}{c}\text { Rho }=0.12 \\
P=0.52\end{array}$ & $\begin{array}{c}\text { Rho }=-0.04 \\
P=0.82\end{array}$ & $\begin{array}{c}\text { Rho }=-0.05 \\
P=0.80\end{array}$ & $\begin{array}{c}\text { Rho }=-0.03 \\
P=0.87\end{array}$ \\
\hline $\begin{array}{l}\text { Number of } \\
\text { comorbidities }\end{array}$ & $\begin{array}{c}\text { Rho }=0.38 \\
P=0.05\end{array}$ & $\begin{array}{c}\text { Rho }=0.08 \\
P=0.69\end{array}$ & $\begin{array}{c}\text { Rho }=0.21 \\
P=0.28\end{array}$ & $\begin{array}{c}\text { Rho }=-0.09 \\
P=0.63\end{array}$ & $\begin{array}{c}\text { Rho }=0.09 \\
P=0.62\end{array}$ & $\begin{array}{c}\text { Rho }=0.08 \\
P=0.66\end{array}$ \\
\hline GDS & $\begin{array}{c}\text { Rho }=0.24 \\
P=0.20\end{array}$ & $\begin{array}{c}\text { Rho }=-0.35 \\
P=0.07\end{array}$ & $\begin{array}{c}\text { Rho }=0.12 \\
P=0.53\end{array}$ & $\begin{array}{c}\text { Rho }=0.12 \\
P=0.52\end{array}$ & $\begin{array}{c}\text { Rho }=-0.29 \\
P=0.13\end{array}$ & $\begin{array}{c}\text { Rho }=-0.16 \\
P=0.40\end{array}$ \\
\hline NRS & $\begin{array}{c}\text { Rho }=0.04 \\
P=0.82\end{array}$ & $\begin{array}{c}\text { Rho }=0.13 \\
P=0.50\end{array}$ & $\begin{array}{c}\text { Rho }=0.12 \\
P=0.54\end{array}$ & $\begin{array}{c}\text { Rho }=-0.21 \\
P=0.29\end{array}$ & $\begin{array}{c}\text { Rho }=-0.11 \\
P=0.57\end{array}$ & $\begin{array}{c}\text { Rho }=-0.12 \\
P=0.52\end{array}$ \\
\hline Laitinen Scale & $\begin{array}{c}\text { Rho }=0.20 \\
P=0.30\end{array}$ & $\begin{array}{c}\text { Rho }=0.09 \\
P=0.64\end{array}$ & $\begin{array}{c}\text { Rho }=0.18 \\
P=0.35\end{array}$ & $\begin{array}{c}\text { Rho }=-0.20 \\
P=0.29\end{array}$ & $\begin{array}{c}\text { Rho }=-0.14 \\
P=0.47\end{array}$ & $\begin{array}{c}\text { Rho }=-0.13 \\
P=0.51\end{array}$ \\
\hline Fext $(\mathrm{N})$ & $\begin{array}{c}\text { Rho }=-0.54 \\
P=0.005\end{array}$ & $\begin{array}{c}\text { Rho }= \\
-0.005 \\
\mathrm{P}=0.98\end{array}$ & $\begin{array}{c}\text { Rho }=-0.39 \\
P=0.04\end{array}$ & $\begin{array}{c}\text { Rho }=0.40 \\
P=0.04\end{array}$ & $\begin{array}{c}\text { Rho }=0.09 \\
P=0.64\end{array}$ & $\begin{array}{c}\text { Rho }=0.15 \\
P=0.44\end{array}$ \\
\hline $\begin{array}{l}\text { Fext/kg body } \\
\text { mass (N/kg) }\end{array}$ & $\begin{array}{c}\text { Rho }=-0.29 \\
P=0.14\end{array}$ & $\begin{array}{c}\text { Rho }=0.12 \\
P=0.53\end{array}$ & $\begin{array}{c}\text { Rho }=-0.23 \\
P=0.24\end{array}$ & $\begin{array}{c}\text { Rho }=0.50 \\
P=0.01\end{array}$ & $\begin{array}{c}\text { Rho }=0.21 \\
P=0.27\end{array}$ & $\begin{array}{c}\text { Rho }=0.31 \\
P=0.11\end{array}$ \\
\hline Fflex $(\mathrm{N})$ & $\begin{array}{c}\text { Rho }=-0.44 \\
P=0.02\end{array}$ & $\begin{array}{c}\text { Rho }=-0.19 \\
P=0.32\end{array}$ & $\begin{array}{c}\text { Rho }=-0.29 \\
P=0.13\end{array}$ & $\begin{array}{c}\text { Rho }=0.22 \\
P=0.24\end{array}$ & $\begin{array}{c}\text { Rho }=-0.30 \\
P=0.12\end{array}$ & $\begin{array}{c}\text { Rho }=-0.19 \\
P=0.32\end{array}$ \\
\hline $\begin{array}{l}\text { Fflex/kg body } \\
\text { mass (N/kg) }\end{array}$ & $\begin{array}{c}\text { Rho }=-0.31 \\
P=0.11\end{array}$ & $\begin{array}{c}\text { Rho }=-0.08 \\
P=0.70\end{array}$ & $\begin{array}{c}\text { Rho }=-0.26 \\
P=0.17\end{array}$ & $\begin{array}{c}\text { Rho }=0.54 \\
P=0.005\end{array}$ & $\begin{aligned} \text { Rho } & =-0.004 \\
P & =0.98\end{aligned}$ & $\begin{array}{c}\text { Rho }=0.16 \\
P=0.39\end{array}$ \\
\hline $\operatorname{Pmax}(\mathrm{W})$ & $\begin{array}{c}\text { Rho }=-0.45 \\
P=0.02\end{array}$ & $\begin{array}{c}\text { Rho }=-0.06 \\
P=0.74\end{array}$ & $\begin{array}{c}\text { Rho }=-0.19 \\
P=0.34\end{array}$ & $\begin{array}{c}\text { Rho }=0.11 \\
\mathrm{P}=0.55\end{array}$ & $\begin{array}{c}\text { Rho }=-0.18 \\
P=0.34\end{array}$ & $\begin{array}{c}\text { Rho }=-0.09 \\
P=0.66\end{array}$ \\
\hline $\begin{array}{l}\text { Pmax/kg body } \\
\operatorname{mass}(\mathrm{N} / \mathrm{kg})\end{array}$ & $\begin{array}{c}\text { Rho }=-0.31 \\
P=0.10\end{array}$ & $\begin{array}{c}\text { Rho }=0.006 \\
P=0.98\end{array}$ & $\begin{array}{c}\text { Rho }=-0.08 \\
P=0.68\end{array}$ & $\begin{array}{c}\text { Rho }=0.30 \\
P=0.12\end{array}$ & $\begin{array}{c}\text { Rho }=-0.09 \\
P=0.63\end{array}$ & $\begin{array}{c}\text { Rho }=0.06 \\
P=0.74\end{array}$ \\
\hline Vopt (rpm) & $\begin{array}{c}\text { Rho }=-0.33 \\
P=0.08\end{array}$ & $\begin{array}{c}\text { Rho }=-0.05 \\
P=0.79\end{array}$ & $\begin{array}{c}\text { Rho }=-0.26 \\
P=0.18\end{array}$ & $\begin{array}{c}\text { Rho }=-0.03 \\
P=0.89\end{array}$ & $\begin{array}{c}\text { Rho }=-0.17 \\
P=0.36\end{array}$ & $\begin{array}{c}\text { Rho }=0.06 \\
P=0.74\end{array}$ \\
\hline
\end{tabular}

GDS - Geriatric Depression Scale, NRS - Numeric Pain Scale, Fext - muscle strength of knee extensors, Fflex - muscle strength of knee flexors, Pmax - maximum power, Vopt - optimal shortening velocity. 
to cover the distance in this test. The muscle strength of knee extensors correlated with the highest number of tests. The greater the muscle strength of knee extensors the patient showed, the better the results obtained in functional tests. The muscle strength of knee flexors and the maximum muscle power determined the result of the Up\&go test. With the increase in the force generated by the knee flexors and the maximum muscle power, the final result of this test improved.

Factors affecting muscle strength and power in patients with lumbosacral spine pain syndromes are shown in Table 4.

Younger patients were characterized by greater muscle strength of knee flexors, maximum muscle power and optimal shortening velocity. Growth had a great influence on the parameters determining muscle function.
The taller the patient was, the greater the muscle strenght of knee flexors he could generate and the greater maximum muscle power he showed. Having more chronic diseases lowered the optimal shortening velocity. Deterioration of mood, assessed with the GDS scale, determined the reduction of muscle strenght of knee extensors. In most cases, the parameters determining muscle function were correlated.

\section{Discussion}

On the basis of the conducted studies, functional deficits can be observed in patients with back pain syndromes. Patients from the study group obtained significantly weaker results in the five-time standing up test, in

Tab. 4. Factors affecting muscle strength and power in patients with lumbosacral spine pain syndromes $(\mathrm{n}=28)$

\begin{tabular}{|c|c|c|c|c|}
\hline & Fext (N) & Fflex $(\mathrm{N})$ & $\operatorname{Pmax}(\mathrm{W})$ & Vopt (rpm) \\
\hline Age (years) & $\begin{array}{c}\text { Rho }=-0.31 \\
P=0.11\end{array}$ & $\begin{array}{c}\text { Rho }=-0.63 \\
P=0.001\end{array}$ & $\begin{array}{c}\text { Rho }=-0.58 \\
P=0.003\end{array}$ & $\begin{array}{c}\text { Rho }=-0.45 \\
P=0.02\end{array}$ \\
\hline Body mass (kg) & $\begin{array}{c}\text { Rho }=-0.06 \\
P=0.75\end{array}$ & $\begin{array}{c}\text { Rho }=0.19 \\
P=0.32\end{array}$ & $\begin{array}{c}\text { Rho }=0.30 \\
P=0.12\end{array}$ & $\begin{array}{c}\text { Rho }=0.24 \\
P=0.22\end{array}$ \\
\hline Growth (m) & $\begin{array}{c}\text { Rho }=0.36 \\
P=0.06\end{array}$ & $\begin{array}{c}\mathrm{Rho}=0.41 \\
\mathrm{P}=0.03\end{array}$ & $\begin{array}{c}\text { Rho }=0.43 \\
P=0.02\end{array}$ & $\begin{array}{c}\text { Rho }=0.17 \\
P=0.39\end{array}$ \\
\hline BMI $\left(\mathrm{kg} / \mathrm{m}^{2}\right)$ & $\begin{array}{c}\text { Rho }=-0.27 \\
P=0.17\end{array}$ & $\begin{array}{c}\text { Rho }=-0.01 \\
P=0.94\end{array}$ & $\begin{array}{c}\text { Rho }=0.09 \\
P=0.63\end{array}$ & $\begin{array}{c}\text { Rho }=0.17 \\
P=0.38\end{array}$ \\
\hline $\begin{array}{l}\text { Number of years } \\
\text { of education }\end{array}$ & $\begin{array}{c}\text { Rho }=-0.03 \\
P=0.86\end{array}$ & $\begin{array}{c}\text { Rho }=0.03 \\
P=0.86\end{array}$ & $\begin{array}{c}\text { Rho }=0.02 \\
P=0.92\end{array}$ & $\begin{array}{c}\text { Rho }=0.11 \\
P=0.56\end{array}$ \\
\hline $\begin{array}{l}\text { Duration of back } \\
\text { problems (years) }\end{array}$ & $\begin{array}{c}\text { Rho }=-0.19 \\
P=0.32\end{array}$ & $\begin{array}{c}\text { Rho }=-0.26 \\
P=0.17\end{array}$ & $\begin{array}{c}\text { Rho }=0.11 \\
\mathrm{P}=0.56\end{array}$ & $\begin{array}{c}\text { Rho }=0.18 \\
P=0.36\end{array}$ \\
\hline $\begin{array}{l}\text { Number of } \\
\text { comorbidities }\end{array}$ & $\begin{array}{c}\text { Rho }=-0.12 \\
P=0.55\end{array}$ & $\begin{array}{c}\text { Rho }=-0.18 \\
P=0.34\end{array}$ & $\begin{array}{c}\text { Rho }=-0.30 \\
P=0.12\end{array}$ & $\begin{array}{c}\text { Rho }=-0.38 \\
P=0.05\end{array}$ \\
\hline GDS & $\begin{array}{c}\text { Rho }=-0.43 \\
P=0.03\end{array}$ & $\begin{array}{c}\text { Rho }=-0.20 \\
P=0.29\end{array}$ & $\begin{array}{c}\text { Rho }=-0.17 \\
P=0.38\end{array}$ & $\begin{array}{c}\text { Rho }=-0.14 \\
P=0.45\end{array}$ \\
\hline NRS & $\begin{array}{c}\text { Rho }=-0.20 \\
P=0.29\end{array}$ & $\begin{array}{c}\text { Rho }=0.18 \\
P=0.35\end{array}$ & $\begin{array}{c}\text { Rho }=0.27 \\
P=0.16\end{array}$ & $\begin{array}{c}\text { Rho }=0.30 \\
P=0.12\end{array}$ \\
\hline Laitinen Scale & $\begin{array}{c}\text { Rho }=-0.25 \\
P=0.20\end{array}$ & $\begin{array}{c}\text { Rho }=0.06 \\
P=0.76\end{array}$ & $\begin{array}{c}\text { Rho }=-0.08 \\
P=0.66\end{array}$ & $\begin{array}{c}\text { Rho }=0.07 \\
P=0.71\end{array}$ \\
\hline Fext $(\mathrm{N})$ & & $\begin{array}{c}\mathrm{Rho}=0.64 \\
\mathrm{P}<0.001\end{array}$ & $\begin{array}{c}\text { Rho }=0.51 \\
P=0.009\end{array}$ & $\begin{array}{c}\text { Rho }=0.29 \\
P=0.13\end{array}$ \\
\hline Fflex $(\mathrm{N})$ & $\begin{array}{c}\text { Rho }=0.65 \\
\mathrm{P}<0.001\end{array}$ & & $\begin{array}{c}\mathrm{Rho}=0.66 \\
\mathrm{P}<0.001\end{array}$ & $\begin{array}{c}\text { Rho }=0.52 \\
P=0.007\end{array}$ \\
\hline $\operatorname{Pmax}(\mathrm{W})$ & $\begin{array}{c}\text { Rho }=0.48 \\
P=0.01\end{array}$ & $\begin{array}{c}\text { Rho }=0.66 \\
\mathrm{P}<0.001\end{array}$ & & $\begin{array}{c}\text { Rho }=0.71 \\
\mathrm{P}<0.001\end{array}$ \\
\hline Vopt (rpm) & $\begin{array}{c}\text { Rho }=0.25 \\
P=0.19\end{array}$ & $\begin{array}{c}\text { Rho }=0.52 \\
P=0.007\end{array}$ & $\begin{array}{c}\text { Rho }=0.71 \\
\mathrm{P}<0.001\end{array}$ & \\
\hline
\end{tabular}

GDS - Geriatric Depression Scale, NRS - Numeric Pain Scale, Fext - muscle strength of knee extensors, Fflex - muscle strength of knee flexors, Pmax - maximum power, Vopt - optimal shortening velocity. 
the Tinetti test and at the level of the tendency to appear statistically significant difference also in the Up\&go test. These results are also confirmed by the studies of other authors. In the work of Lavky-Shulan et al. [12] decreased functional efficiency was found in patients suffering from pain in the lumbosacral spine. Patients showed functional limitations in walking, sitting, bending and housework. Pain largely determined their level of physical activity. In the study of Kozłowski et al. [13], people in the 60-75 age group much more often chose higher values in the Numeric Pain Scale, which contributed to a reduction in their functional efficiency. Cecchi et al. [14] observed that in older patients, back pain was associated with decreased physical activity as well as deterioration of the mental state of patients and difficulties in doing household activities, shopping and using public transport. In our study, patients with back pain had lower results in functional tests, but the level of pain alone did not determine these results. This may be due to the fact that the study included people in a chronic condition, with less pain. In our reality, the patient goes to facilities that provide physiotherapy services after a long waiting period, which often leads to a spontaneous reduction in pain and the need to participate in daily activities.

In terms of functional ability, the results of the Up\&go test were associated with the greatest number of factors. No relationship was obtained with the Barthel Index, which results from the occurrence of the socalled ceiling effect for this test. The mean score for both the study and control groups was almost equal to the maximum number of points that could be achieved in this study, which indicates a fairly good functional level in terms of basic daily activities.

In the group of patients with pain syndromes, the Up\&go result was influenced by age - worse results were obtained by older patients. The influence of age on functional ability is commonly described in the works of other authors. Changes related to ageing affect almost all structures and functions of the organism, moreover, the number of chronic diseases increases, which in turn leads to a reduction in the possibility of efficient functioning $[15,16]$. The decrease in functional efficiency is also influenced by the deterioration of muscle function, which was also confirmed in the present study. Older patients had poorer results for almost all muscle assessment parameters, i.e. strength, power, and optimal shortening velocity.

In our research, we can observe a relationship between functional performance measured with the Up\&go test and the number of comorbidities. Szpala et al. in their article [2] indicate that all kinds of birth defects and anomalies, degenerative changes, joint inflammation, neoplastic and metabolic diseases, as well as injuries and overload diseases, to a large extent intensify the pain in the spine, and may even be their direct cause. Patients from the study group (with back pain) also had a greater number of chronic diseases compared to the control group. Therefore, it cannot be ruled out that the results of both functional ability and muscle function in our study were also influenced by other chronic diseases. This is a weakness of the study and in this respect it is worth carrying out additional analyzes in the future, including a larger group of patients.

The strength of the muscles of the lower limbs is an important factor influencing the functional efficiency of patients with back pain syndromes. Patients with back pain syndromes who generated greater muscle strength in the lower extremities achieved better results in functional tests. As in our study, de Sousa et al. [17] in a systematic review with meta-analysis showed that patients suffering from lumbosacral spine pain were characterized by a reduced muscle strength of knee extensors (additionally the abduction and straightening muscles in the hip joint), but there was no significant difference in the muscle strength of knee flexors compared to healthy patients. The largest number of clinical trials involving patients with back pain concerns the strength of the trunk muscles, only a few studies concern the strength of other muscle groups. Meanwhile, the muscles of the lower extremities can greatly influence the position of the pelvis. In addition, the strength of individual human muscles is usually correlated with each other: a patient who shows weaker muscle strength in the lower limbs, at the same time usually has weaker trunk muscles. Lee et al. [18] emphasize the reduced strength of the trunk muscles and the knee joint muscles in patients with pain in the lumbosacral spine, and emphasize the correlation between the total strength of the trunk muscles and the muscles of the knee joint in both the control and study groups.

In the general population of the elderly, according to the results of research by many authors $[9,15,19]$, muscle power and the optimal shortening velocity determine to a greater extent functional efficiency than muscle strength. For example, in studies by Clemencon et al. [19] it was found that the maximum muscle power and the optimal shortening velocity are determinants of physical ability and are an extremely important factor determining patient mobility. Studies conducted in a group of women with chronic osteoarthritis have shown that the improvement in functional ability after rehabilitation is mainly due to changes in the maximum muscle power and the optimal shortening velocity in these patients, and to a lesser extent is related to the change in muscle strength [9]. In our research, the relationship between muscle power and functional efficiency concerned only the Up\&go test, and in the case 
of speed, it tended to be statistically significant. If more patients were included in the study, this relationship could be more pronounced, therefore it is advisable to continue research in this area with a larger group of patients.

\section{Conclusions}

1. Patients with back pain syndromes are characterized by reduced functional performance and have deficits in the muscle strength of knee extensors compared to people without back pain.

2. The muscle strength of knee extensors has the greatest influence on functional performance in patients with back pain syndromes.

3. Age is the strongest determinant of muscle function. Older patients are characterized by both weaker muscle strength and power, and the optimal shortening velocity.

\section{Funding}

This research received no external funding.

\section{Conflicts of interest}

The authors declare no conflict of interest.

\section{References}

1. Hartvigsen J, Hancock MJ, Kongsted A et al. What low back pain is and why we need to pay attention. Lancet. 2018; 391(10137): 2356-67.

2. Szpala M, Skorupińska A, Kostorz K. Occurrence of back pain syndromes - causes and treatment. Pomeranian J Life Sci. 2017; 63(3): 41-7.

3. Kałużna A, Kałużny K, Wołowiec Ł, Płoszaj O, Zukow W, Kochański B et al. Prevention of back pain - literature review. Cent Eur J Sport Sci Med. 2017; 7(7): 912-26.

4. Chiou SY, Koutsos E, Georgiou P, Strutton PH. Association between spectral characteristics of paraspinal muscles and functional disability in patients with low back pain: a cohort study. BMJ Open. 2018; 8(2).

5. Verbunt JA, Seelen HA, Vlaeyen JW, Bousema EJ, van der Heijden GJ, Heuts PH et al. Pain-related factors contributing to muscle inhibition in patients with chronic low back pain: an experimental investigation based on superimposed electrical stimulation. Clin J Pain. 2005; 21(3): 232-340.

6. Ronikier A. Functional diagnostics in physiotherapy. Warsaw: PZWL; 2012.

7. Gupta A, Yadav R, Malhotra AK. Assessment of physical disability using Barthel index among elderly of rural areas of district Jhansi (U.P), India. J Family Med Prim Care. 2016; 5(4): 853-7.

8. Wieczorowska-Tobis K, Talarska D. Geriatrics and geriatric nursing. Warsaw: PZWL; 2014.

9. Benzon HT, Srinivasa RN, Fishman SM, Liu SS, Cohen SP. Essentials od Pain Medicine. 4th ed. Amsterdam: Elsevier; 2018.

10. Polański J, Chudiak AK, Rosińczuk J. Qestionnaires used in the assessment of selected symptoms of lung cancer. Med Paliat Prakt. 2016; 10(3): 89-97.

11. Kostka JS, Czernicki JW, Kostka TJ. Association of muscle strength, power, and optimal shortening velocity with functional abilities of women with chronic osteoarthritis participating in a multi-modal exercise program. J Aging Phys Act. 2014; 22(4): 564-70.

12. Lavsky-Shulan M, Wallace RB, Kohout FJ, Lemke JH, Morris MC, Smith IM. Prevalence and functional correlates of low back pain in the elderly: the lowa 65+ Rural Health Study. J Am Geriatr Soc. 1985; 33(1): 23-8.

13. Kozłowski P, Kożuch K, Kozłowska M, Ławnicka I, Kozłowska K. Assessment of the prevalence of back pain as well as the lifestyle and quality of life among people with back pain. J Educ Health Sport. 2016; 6(6): 329-36.

14. Cecchi F, Debolini P, Molino Lova R, Macchi C, Bandinelli S, Bartali B et al. Epidemiology of Back Pain in a Representative Cohort of Italian Persons 65 Years of Age and Older: The InCHIANTI Study. Spine. 2016; 31(10): 1149-55.

15. Byrne C, Faure C, Keene DJ, Lamb SE. Ageing, Muscle Power and Physical Function: A Systematic Review and Implications for Pragmatic Training Interventions. Sports Med. 2016; 46(9): 1311-32.

16. Ramnath U, Rauch L, Lambert EV, Kolbe-Alexander TL. The relationship between functional status, physical fitness and cognitive performance in physically active older adults: A pilot study. PLoS One. 2018; 13(4).

17. de Sousa CS, de Jesus FLA, Machado MB, Ferreira G, Ayres IGT, de Aquino LM et al. Lower limb muscle strength in patients with low back pain: a systematic review and meta-analysis. J Musculoskelet Neuronal Interact. 2019; 19(1): 69-78.

18. Lee JH, Ooi Y, Nakamura K. Measurement of muscle strength of the trunk and the lower extremities in subjects with history of low back pain. Spine. 1995; 20(18): 1994-6.

19. Clémençon M, Hautier CA, Rahmani A, Cornu C, Bonnefoy M. Potential role of optimal velocity as a qualitative factor of physical functional performance in women aged 72 to 96 years. Arch Phys Med Rehabil. 2008 ; 89(8): 1594-9. 